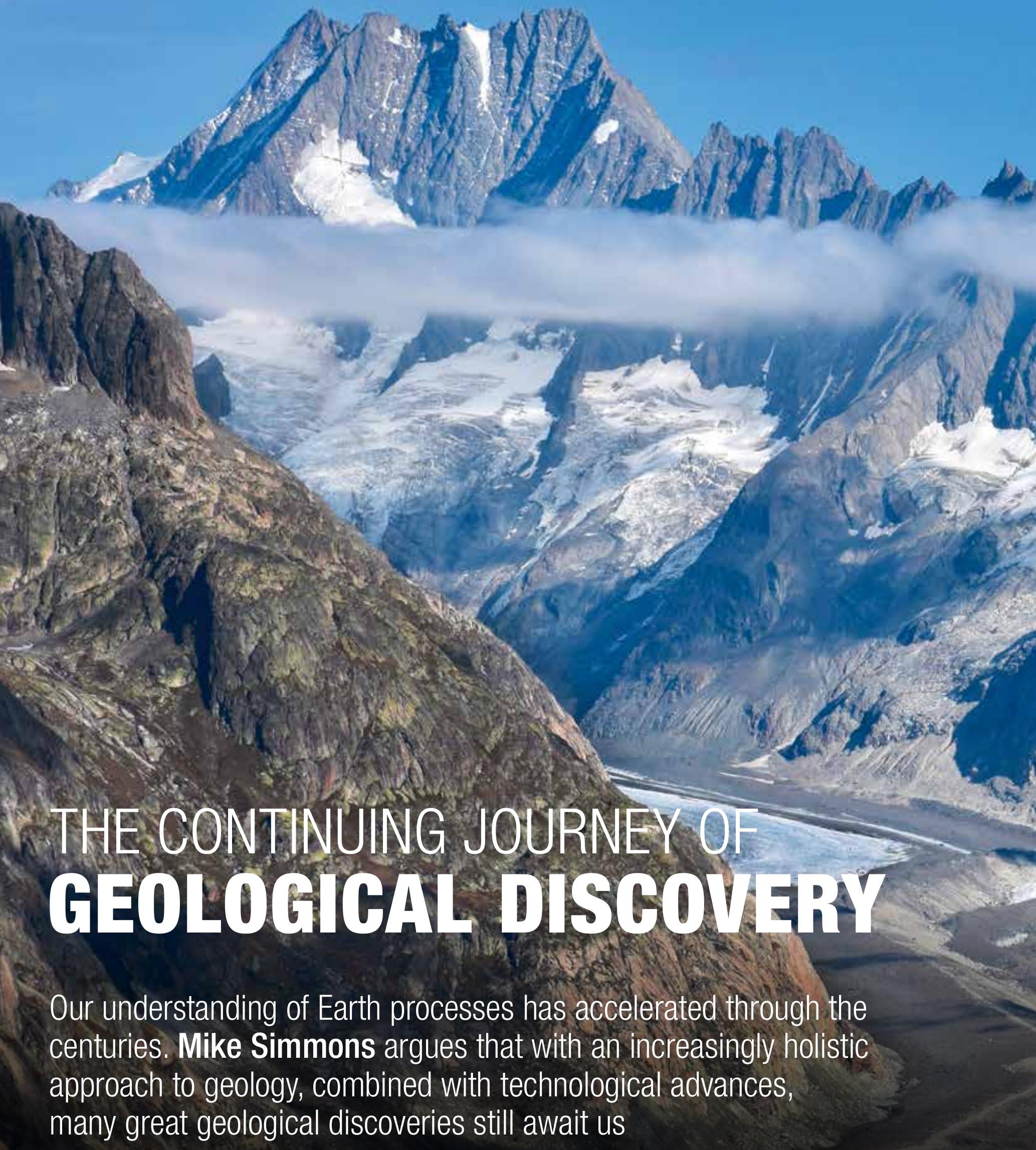



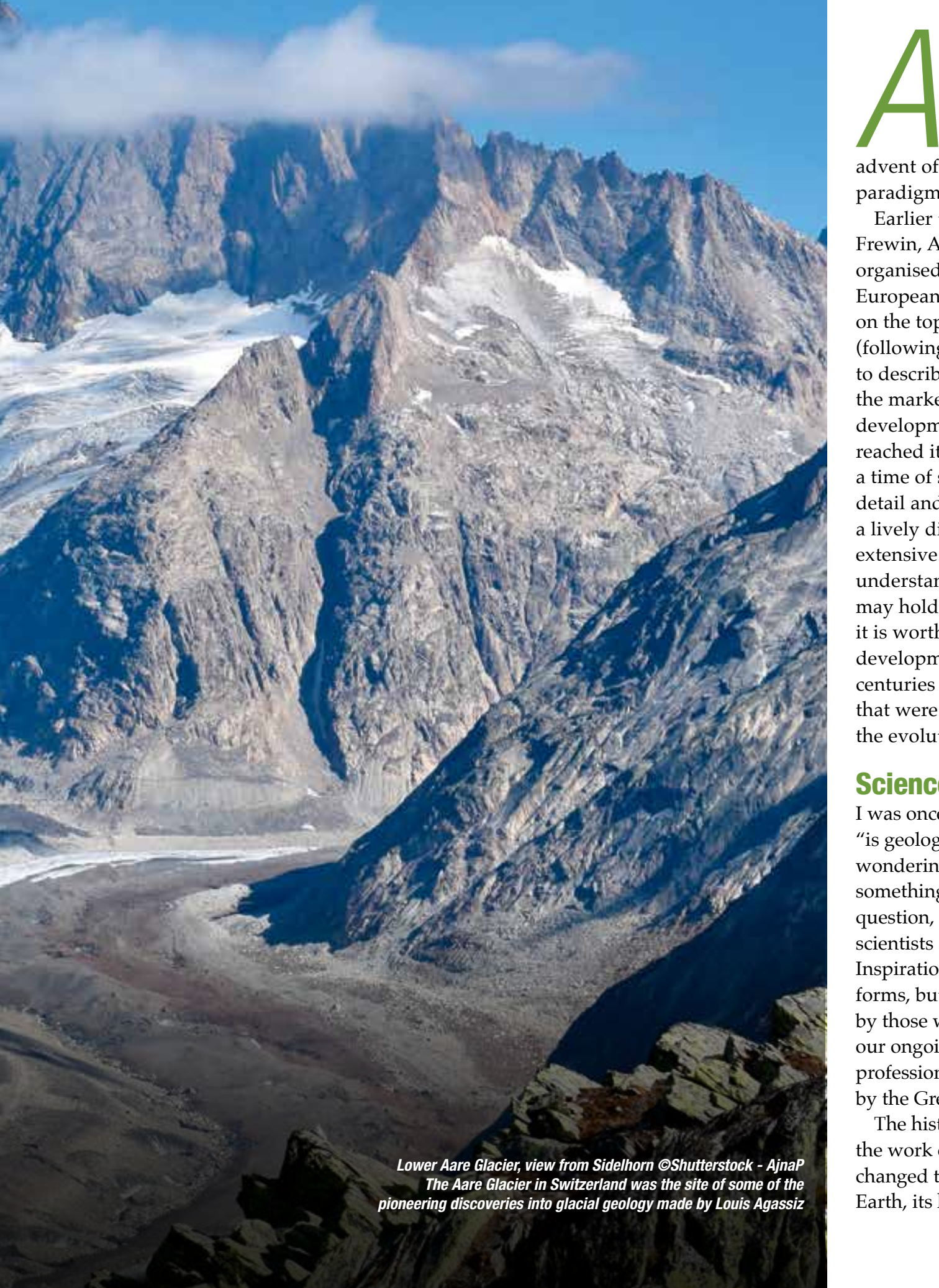

dvances in geoscience are made every day by geologists working in the field,

laboratory or office. Yet, it is now over fifty years since the advent of plate tectonics, the last great paradigm shift in geoscience.

Earlier this year, I, together with Neil Frewin, Andy Davies and Helen Cromie, organised a session at the annual

European Geosciences Union meeting on the topic of "Peak Geoscience" (following on from the term "Peak Oil" to describe the time of peak oil supply to the market). In other words, has our development of geological science reached its zenith? Have we entered into a time of synthesis, the gathering of detail and of consolidation? We enjoyed a lively discussion and now plan a more extensive meeting for 2020. To understand what the future of geology may hold, and if we really are at a peak, it is worth looking back to the development of the science over the centuries and to understand the leaps that were made in our understanding of the evolution of Earth and its processes.

\section{Science or art}

I was once asked during a job interview "is geology a science or an art?" I am still wondering what the correct answer is to something that sounds like a trick question, but what I do know is that both scientists and artists require inspiration. Inspiration can come in all manner of forms, but we can definitely be inspired by those who have paved the way for our ongoing endeavours. For our profession, that means being inspired by the Great Geologists.

The history of geoscience is marked by the work of exemplary scientists who changed the way we think about the Earth, its history, processes and 
Fig 1: James Hutton [1726-97]

in the field.

Illustration in: Original Portraits and Caricature Etchings, 1877, v. 1, oppos, p. 55. (by John Kay [Public domain]). Note that the outcrop shows the profiles of human facesperhaps Hutton is talking to the

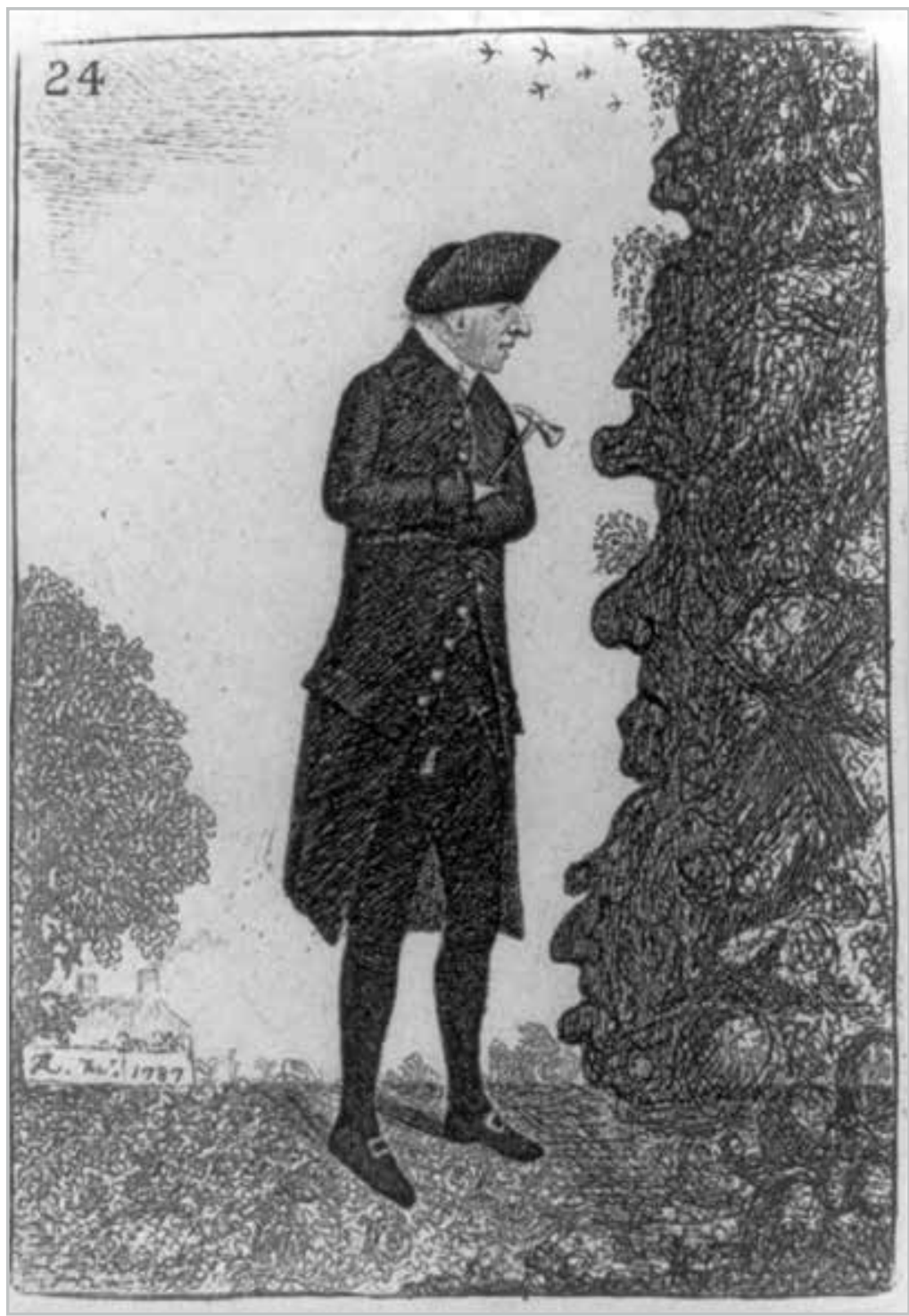

resources. Some made huge intuitive leaps, recognising, for example, the immensity of geological time or the mobility of the continents. Others described rocks, minerals and fossils in the field or laboratory, and provided vital data that allowed theories to develop. Others still embraced new technologies, such as geophysics, that enabled what cannot be observed directly to be interpreted. Many led colourful lives or overcame adverse circumstances. These seem like people worth knowing about, not least for the inspiration they provide.

\section{The journey begins}

The history of geological thinking is a long one, with scholars in both ancient Greece and Rome contemplating the history of Earth and how that related to the rocks beneath their feet. In the 5th century B.C., Xanthus of Lydia saw shell shapes in rocks now located far from the coast and concluded that these regions must have once been submerged beneath the sea. Centuries later, Leonardo da Vinci drew similar conclusions.

Nonetheless, it was not until the mid- $17^{\text {th }}$ century and the arrival of the Dane Nicolas Steno in Late Renaissance Florence that modern geological thinking can be said to have started. Steno's observations, during his brief dalliance with geology, were seemingly simple by modern standards: in a normal succession
Fig 2: The

frontispiece from Charles Lyell's Principles of Geology (second American edition, 1857), showing the origins of different rock types. (Charles Lyell [Public domain]). By the mid-19th century, envisaging the complexities of subsurface geology was possible

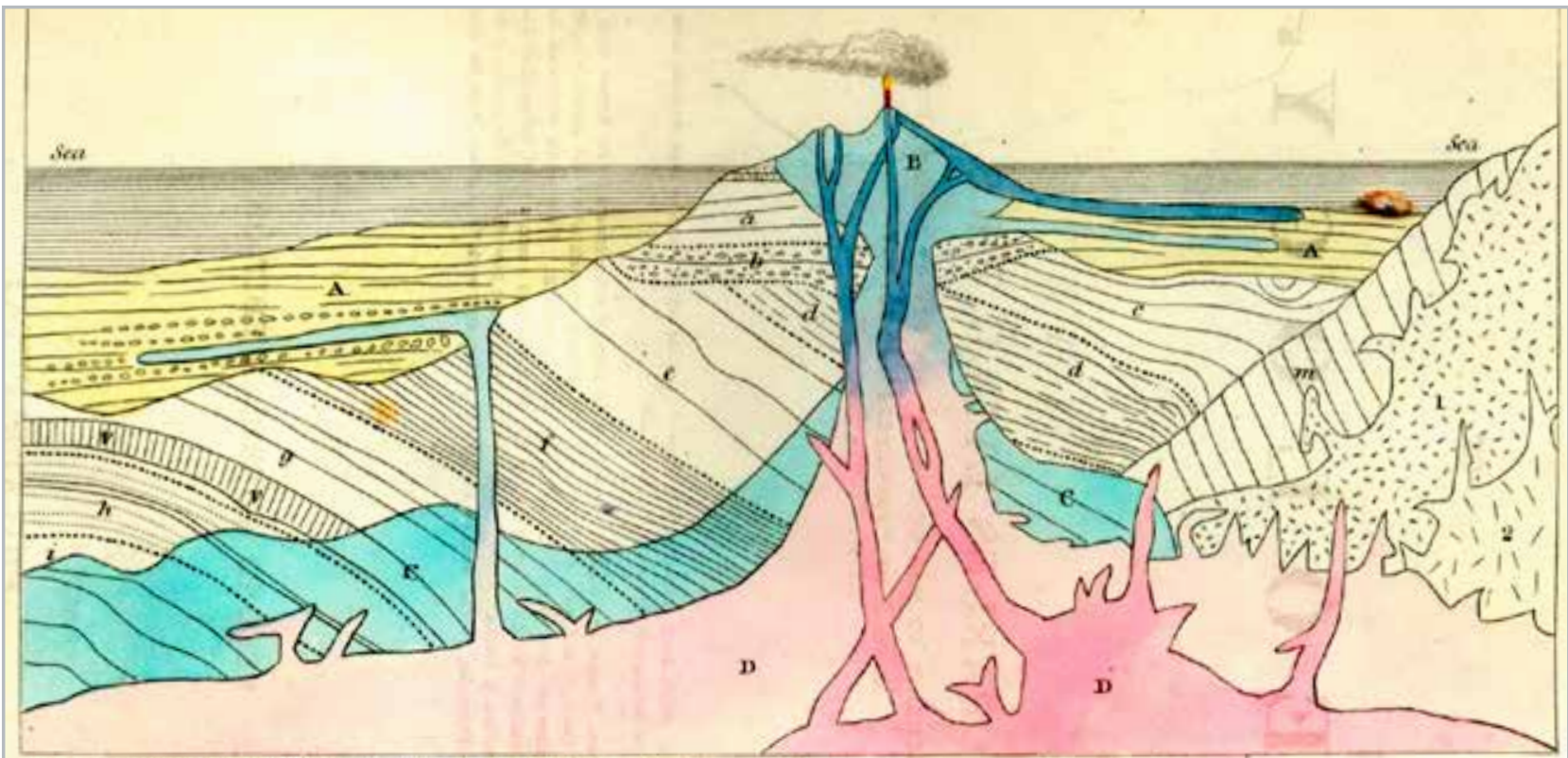

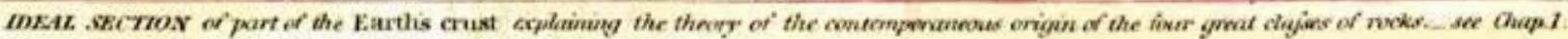


of rocks, the oldest are at the bottom and the youngest at the top; sedimentary rocks are laid down horizontally; if they are not horizontal, then they have been folded or faulted; and fossils are the preserved remains of ancient creatures. Yet, these notions suggested that the rock record and its fossil content represented a chronology, effectively a book of Earth history, waiting to be read.

It was not until over 100 years later that the book of Earth history began to be read in earnest. During the Age of

Enlightenment, the Scottish intellectual, James Hutton (Fig. 1), argued from a

consideration of the processes creating rocks and their subsequent deformation that the age of Earth had to be immense by human standards ("the abyss of time" as described by Hutton's friend and fellow intellectual, John Playfair). How immense was uncertain, but certainly much older than might be determined from a literal interpretation of the Bible, or other religious texts.

\section{Geology takes shape}

Geology as a stand-alone subject was born in the late 18th century with the work of Hutton and others. Hutton was not the "Father of Geology" as he is sometimes portrayed, but he was an important catalyst in developing inductive thinking about the age of Earth and geological processes. Others, such as Abraham Gottlob Werner, Georges Louis Leclerc, Comte de Buffon and Peter Pallas, were contemplating similar issues in Germany, France and Russia respectively. Around the time of Hutton, in 1778, geology as a term with its current meaning was introduced by the Genevabased naturalist Jean-André Deluc. (It had been in use since the 15th century as the Latin word geologia, which had a broader meaning that included the study of plants and animals.)

Werner and Hutton were on opposite sides of the controversy between "Neptunists" and "Plutonists", which occupied geological, and indeed popular, thinking in the late $18^{\text {th }}$ century. Werner had promoted the notion that all rocks, including granites and basalts, were either deposited or precipitated out of water ("Neptunism"), whilst Hutton favoured the plutonic view that granites and basalts were the products of heat within Earth creating molten magma

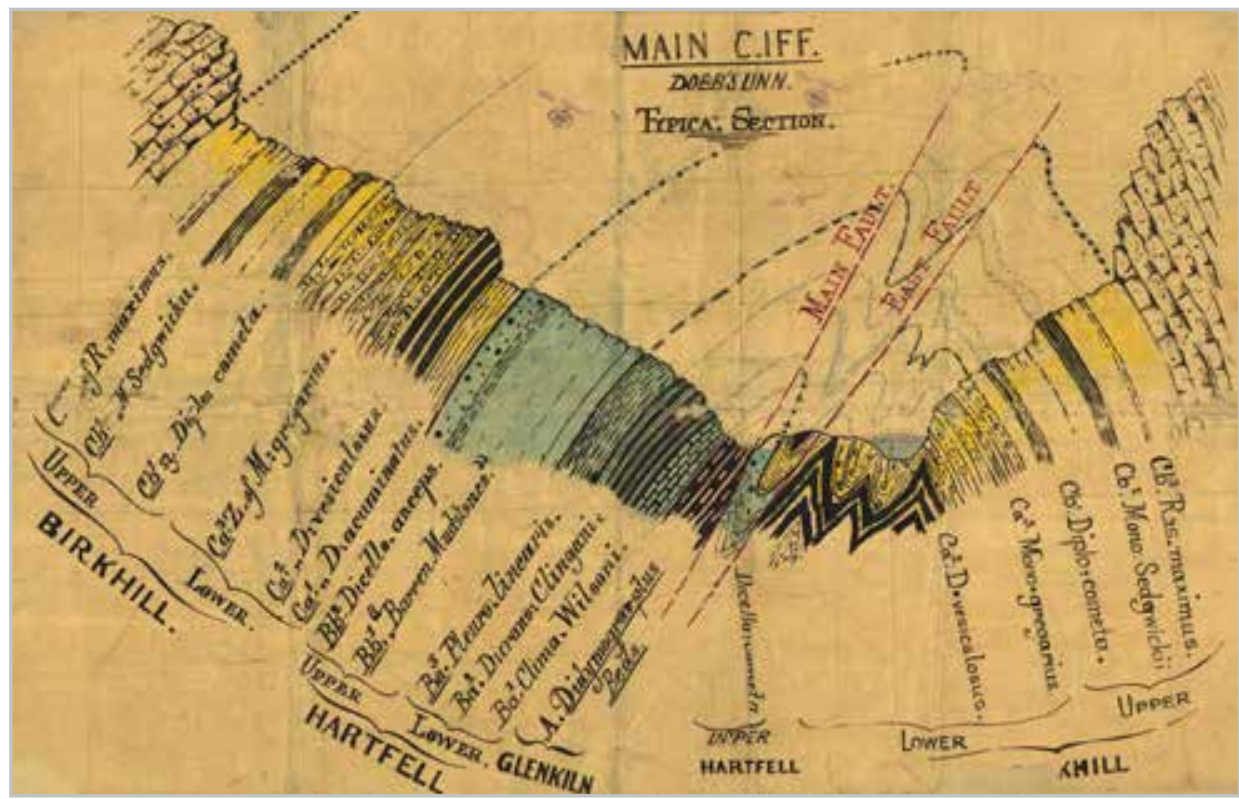

Fig 3: By the mid-19th Century, biostratigraphy and structural geology were being combined effectively as demonstrated in this hand drawn field sketch by Charles Lapworth of Paleozoic rocks in the Southern Uplands of Scotland. Image provided by and used with the kind permission of the Lapworth Museum of Geology, University of Birmingham.

("Plutonism"). His observation of cross-cutting intrusions demonstrated this. By the beginning of the $19^{\text {th }}$ century, Neptunism as an explanation for crystalline rocks, such as granite, was effectively no longer in vogue. Instead, rock classifications concentrated on the concepts we now know as igneous, metamorphic and sedimentary.

The next major step in the history of geology was to determine that the fossil content of sedimentary rocks could be used as a key to understanding that a given rock unit could be associated with a specific period of Earth history. This allowed correlation to other rocks deposited during the same period-the science of stratigraphy was born. Recognition of distinct strata permitted the mapping of these layers as they occurred at Earth's surface and, equally importantly, enabled a prediction to be made of what might lie below the surface. William Smith in England and Georges Cuvier in France pioneered this thinking at the end of the $18^{\text {th }}$ century into the beginning of the $19^{\text {th }}$ century.

\section{Earth history vs processes}

Geological research focused on two distinct activities for the first half of the 19th century. There were those concerned with the description and classification of rocks, minerals and fossils and, most notably, the subdivision of Earth history. British geologists such as Sir Roderick
Murchison and Adam Sedgewick were at the forefront of this campaign, with European counterparts such as Alcide d'Orbigny not far behind.

Other researchers were concerned with the geological processes operating on and within Earth, as well as how these processes may have operated in the geological past. In other words, how rocks came to be formed and subsequently deformed. Foremost amongst these was Sir Charles Lyell (Fig. 2), who considered himself on a crusade to make geology scientific. Observations led to theories about how geological processes operated. In Lyell's view, these processes were gradualistic-a steady state Earth in which geological processes were the same in the past ("Uniformitarianism", following on from ideas earlier expressed by Hutton). By contrast, many geologists in continental Europe favoured the theory promoted by Georges Cuvier that Earth had experienced a more eventful past, with catastrophes punctuating Earth history, these events being associated with tectonics, extinctions and major changes in deposition ("Catastrophism").

The debate of the importance of Uniformitarianism versus Catastrophism continued throughout much of the $19^{\text {th }}$ century and persists in some circles even today; although most geologists are now happy to accept that 
Earth history is a response to a combination of both gradual and sudden processes.

However, many $19^{\text {th }}$ century geologists (as today) were both describers/ classifiers and interpreters, attempting to add colour to the pages of Earth history by envisaging past worlds. What did a Jurassic Earth look like and what creatures inhabited it? Which geological processes were operating to leave us with the rock record we see today? Such intriguing questions are equally valid nowadays and engage the imagination of most geologists to a greater or lesser extent, even if their focus is often on the fine detail. The romance of imagining our past Earth is something that still draws students to study geology and requires both an understanding of geological classification and of geological processes.

By the second half of the $19^{\text {th }}$ century, much of the basic classification work had been completed (although this continues to the present day in order to provide ever-increasing precision) and greater numbers of geological scholars were focused on interpreting the rocks they studied in terms of the processes responsible for their creation and deformation. Such studies ranged from the small-scale, for example, Henry
Sorby and his interpretation of rocks in thin-section under the microscope, to the large scale, such as Eduard Suess and his interpretation of the formation of mountain belts. Geological disciplines were becoming increasingly integrated (Fig. 3). Although Western Europe continued to be a hub for geological research, American researchers, such as James Dana, Louis Agassiz and T.C. Chamberlin, were now also making important contributions.

\section{Earth's age and rhythms}

Geologists, however, were still faced with the perplexing conundrum-how old was Earth? It was widely accepted to be millions of years in duration, but exactly how many remained an unknown. The discovery of radioactivity, as the $19^{\text {th }}$ century passed into the $20^{\text {th }}$ century, provided the breakthrough. Radioactive decay of elements present in certain rocks could be measured and interpreted in terms of absolute age. At last, there was a clock of Earth history!

The undisputed pioneer of this research was the great British geologist Arthur Holmes. Thanks to Holmes, and those who followed him, geologists could use an understanding of the age of Earth and the duration of the chapters in
Earth history to help elucidate the processes responsible for forming and deforming rocks, and explain modes of evolution represented by the fossil record. Knowledge of true geological time allowed thinking on a grand scale. Alfred Wegener was able to envisage continents drifting on Earth's surface throughout geological time; whilst others, such as T.C. Chamberlin and Amadeus Grabau, began to recognise a rhythm to Earth's sedimentary record. These notions, in turn, spurred the paradigms of plate tectonics and sequence stratigraphy in the second half of the $20^{\text {th }}$ century.

Even though geologists are often asked who 'discovered' plate tectonics, the answer is that no single person can be said to have done so. Papers by Dan McKenzie and Bob Parker or by Jason Morgan can be cited as being the first to describe plate motions as translations and rotations on a sphere, but these built upon a long series of discoveries by many other researchers who worked on the bathymetry of the deep ocean, such as Marie Tharp, the nature of oceanic and continental crust, sea-floor spreading (Fig. 4), transform faults, and convection within Earth's interior. Plate tectonics is arguably the last great geological discovery-the culmination
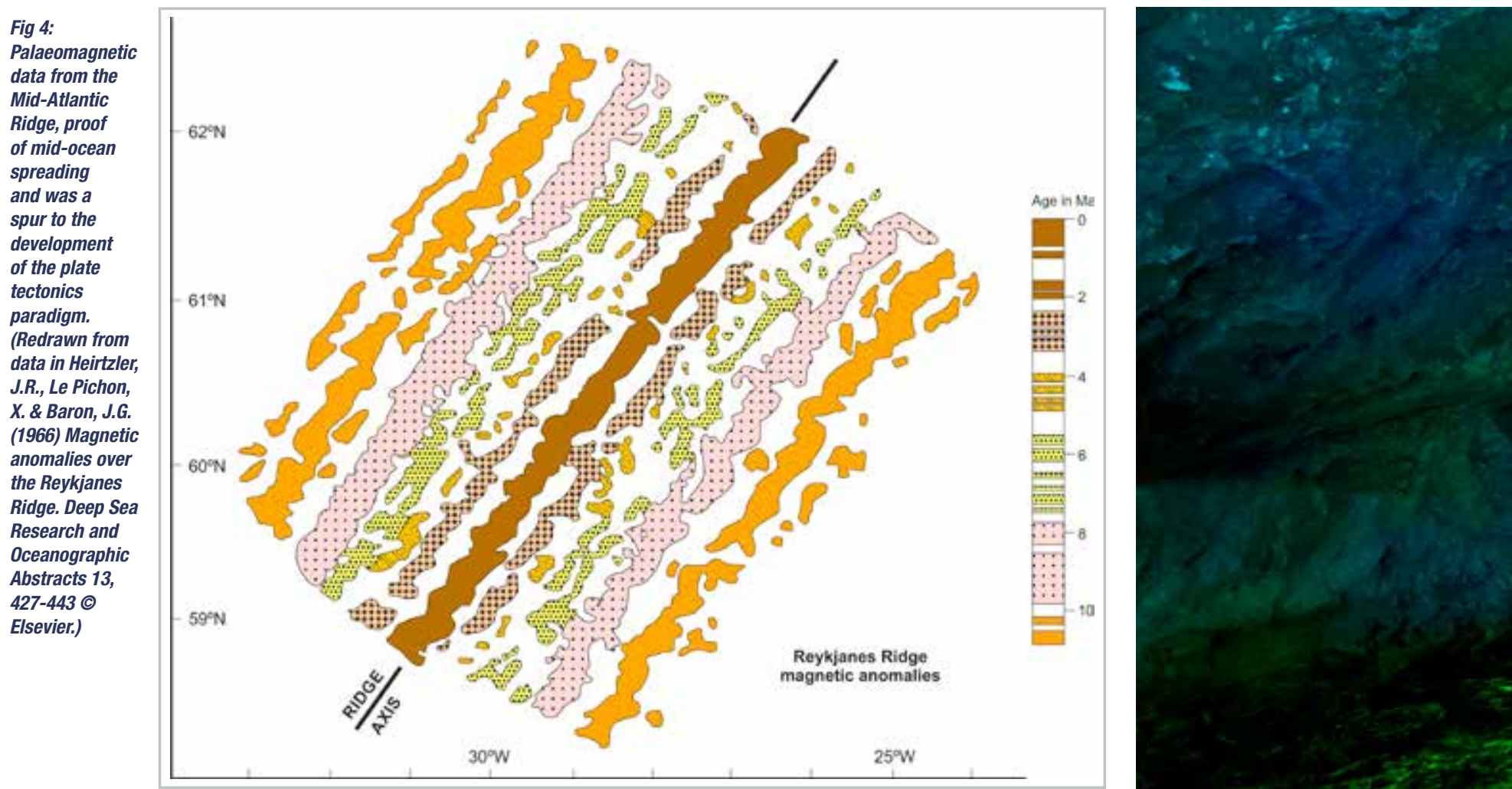


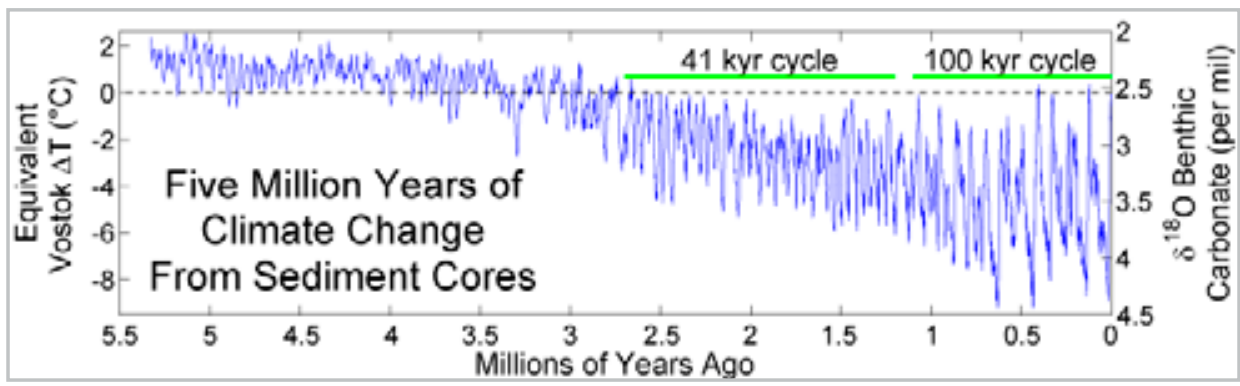

Fig 5: Reconstruction of the past 5.3 million years of climate history, based on oxygen isotope fractionation, serving as a proxy for global palaeotemperature and ice volume. (A version of the LR04 Stack created by Lorraine Lisiecki and Maureen Raymo; Lisiecki, L. \& Raymo, M. (2005) A Pliocene-Pleistocene stack of 57 globally distributed benthic d180 records Paleoceanography 20: PA1003. D0l:10.1029/2004PA001071; Redrawn by Robert A. Rohde and published under a CC BY-SA 3.0 Unported licence and a GNU Free Documentation License).

and integration of understanding geological time and geological processes. Of course, new geological discoveries are made every day, but nothing (as yet!) can compare to the scale of the plate tectonics paradigm.

\section{Looking Forward}

What then of "Peak Geoscience"? Have we really reached a zenith in our understanding? Personally, I doubt this. Obviously, we have not reached complete knowledge, yet major theoretical breakthroughs seem to be lacking. Is that because there is a focus on case studies, compounded by pressure to publish papers to meet performance targets?

On the other hand, geology is becoming increasingly holistic and integrated with other sciences. Earth Systems Science combines a variety of processes operating at the full range of timescales (from hours to millions of years) and spatial contexts (from local depositional processes to global tectonics), thereby providing insight into sediment supply from mountain source to sediment sink within a depositional basin. Palaeoclimate research, such as that carried out by Maureen Raymo (Fig. 5), works in a similar manner, providing insights for modelling of future climate trends.

Alongside such holistic approaches, it is likely that advances in technology and data science will transform geology by teasing out patterns in geological data that are beyond the capacity for easy recognition by humans.

The geologists working before the 20th century went out into the field and made observations that then led to theories of geological processes. During the 20th century, technological breakthroughs made a huge difference to geological thinking. For example, the advent of radiometric dating, the recognition of palaeomagnetism, and the use of geophysical techniques and remote sensing are immense. That does not belie the importance of field work - there is no substitute for gathering data-but rather than armed simply with a hammer, hand-lens, compass-clinometer and paper notebook, the field geologist now has a wider variety and more sophisticated set of tools at their disposal, including drones and 3D imaging technology. Geoscience is far from being at its peak!

Mike Simmons, Technology Fellow for Geosciences \& Exploration at Halliburton, Honorary Professor at the University of London and Scientific Associate of The Natural History Museum.

To encourage others to learn more about the Great Geologists, Mike, with support from Halliburton, has produced a book that reviews the lives and scientific contributions of $\mathbf{3 5}$ of the more significant contributors to our subject. It is freely available as an e-book at https://joom.ag/ggLa and printed copies are available on request whilst stocks last (contact Mike at mike.simmons@halliburton.com).

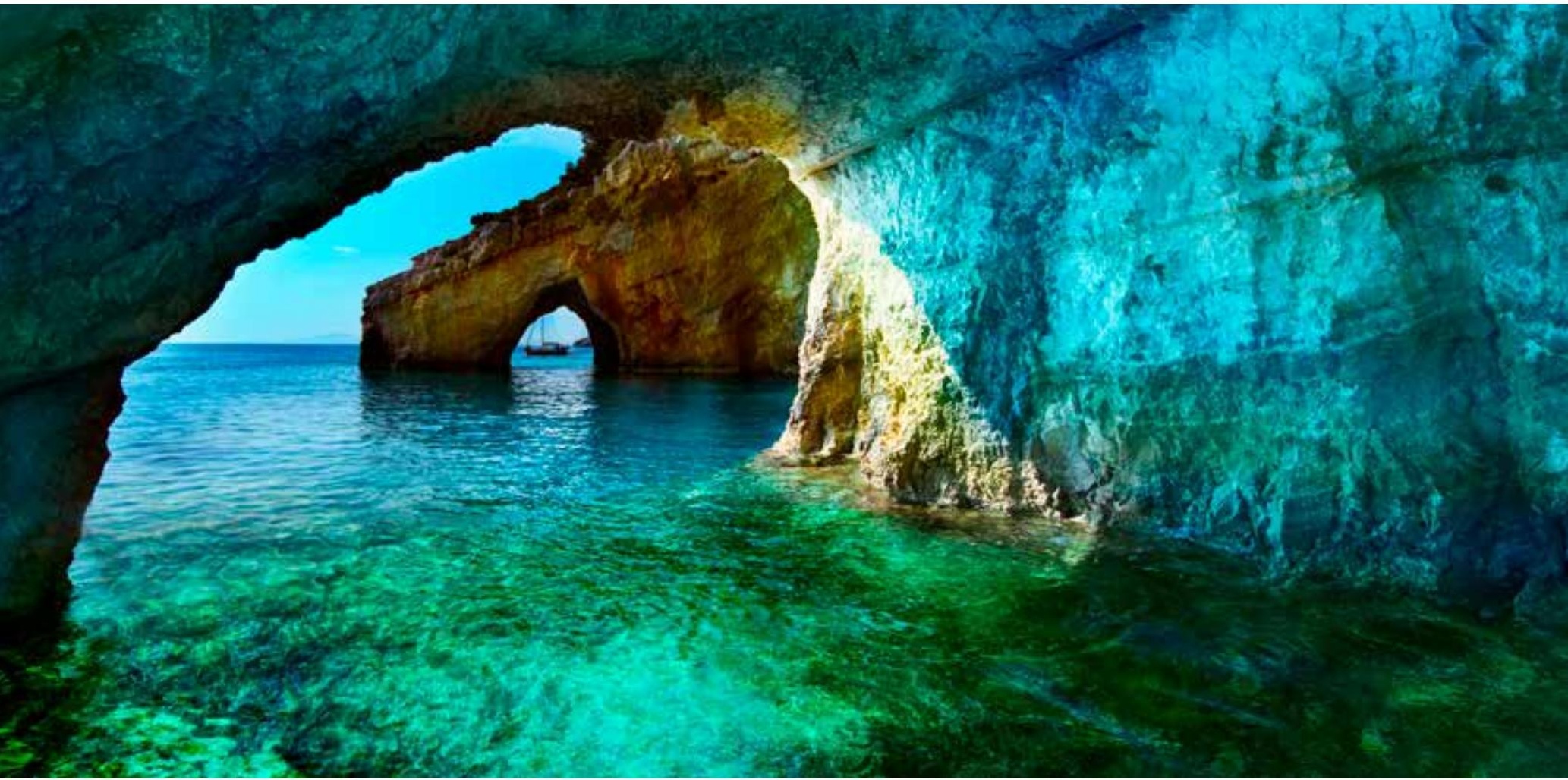

